\title{
The ST(R)E(A)M Methodology in Kindergarten: A Teaching Proposal for Exploratory and Discovery Learning
}

\author{
Paraskevi Foti
}

\section{ABSTRACT}

This paper attempts to present a proposal to teach the natural concepts of hydrodynamics under the $S T(R) E(A) M$ approach. This is a comprehensive teaching proposal for pre-school teachers, with the possibility of implementation in each class, which helps the teacher to enrich his teaching with activities from science, technology, reading and writing, engineering and mathematics, promoting active participation, critical thinking, collaboration, creativity and developing skills necessary for tomorrow's citizens.

Keywords: STREAM, early childhood education, exploratory learning, problem solving About four key words or phrases in alphabetical order, separated by commas.

\section{INTRODUCTION}

In a world that is constantly evolving, kindergarten cannot remain uninvolved in developments, as scientific literacy is essential for life in modern society. The STEM-based education approach aims to prepare children to solve global issues through exploration, discovery, creative and critical thinking, collaboration, effective interaction and communication (Quigley \& Herro, 2016). This is an approach that removes the boundaries between particular cognitive objects and sees them as an "all", on the grounds that modern problems are complex and multidimensional enough to be addressed by a single science (Tsupros et al, 2009). Research carried out in the field of early childhood education with children participating in STEM activities concluded that children's age is not a limiting factor but instead benefits them in developing and cultivating a variety of skills, just as in older children (Kermani \& Aldemir, 2015; Lyons \& Tredwell, 2015; Moomav \& Davis, 2010).

Research has shown that engaging children in the natural sciences at an early age, in combination with other fields such as technology, helps to raise awareness and increase their interest in science (Mantzicopoulos et al, 2009).The objectives of the Interdisciplinary Single Framework of Kindergarten Curriculums(2003) are in line with the objectives and potential benefits of STEM education. In addition, the Kindergarten emphasizes their interdisciplinarity, skills and training, while in the New Analytical Program for kindergarten (2001) there are connections between all learning areas and reference is made to the "basic competences" promoted through it such as communication, creative thinking, personal identity and autonomy, social skills and competences related to citizenship.

\author{
Published Online: January 06, 2021 \\ ISSN: $2736-4534$ \\ DOI : $10.24018 /$ ejedu.2021.2.1.21 \\ F. A. Author* \\ Educational Coordinator in Greek \\ Ministry of Education \\ University of West Attica, Greece \\ *Corresponding Author
}

\section{ST(R)E(A)M CONTENT EPISTEMOLOGY}

The term STEM was first used in 1990 by the NSF (National Science Foundation) to attribute the interconnection of different scientific fields such as Science, Technology, Engineering (Eng and Mathematics while in recent years it has been added to this acronym the $\mathrm{R}$ which is Reading, which is usually combined with Writing and creative thinking. An overview of international literature shows that ST(R)E(A)M education offers multiple benefits to students, such as better problem solving, innovation, ingenuity, belief in their potential as well as enhancing their logical thinking and technological literacy (Morrison, 2006, Bybee, 2010).

According to Stohlman et al., (2012) the integration of mathematics and natural sciences into the school environment has a positive impact on children's behaviour and interest in school, motivation for learning and the integration of goals by children. The STEM approach was designed to introduce the sciences of Engineering and Engineering into the teaching of Mathematics and Natural Sciences. STEM epistemology as an interdisciplinary approach is not only about a teaching model, but also requires the development of artifacts that follow the engineering cycle and the application of Computational Science methods in education. Students can even at young ages become "small Scientists and Engineers" where Engineering could be attributed as "Mechanics", while involved in the concept of "calculation" with real data.

In addition, this approach is based on explorationdiscovery. A class under this approach encourages students 
to work with each other to solve problems using question and answer techniques in conjunction with research. STREAM education is attractive to students as they enjoy discussing and solving essential problems. It offers satisfaction, as teachers participate as mediators and not only as instructors (Roberts, 2012). Learning increases because students share previous knowledge, use the best skills of their peers and tap into each other to discover new and important information

According to Roberts (2012) STEM education is not in itself a curriculum, but a way of organizing teaching. A fully integrated STEM curriculum is more easily implemented in kindergarten and primary school, where students stay with a teacher for a long time during the day compared to secondary school. A well-designed and accessible building material corner in kindergarten can be used to develop STEM activities (Christenson \& James, 2015). The development of programming concepts and algorithmic thinking in preschool children using the programmable Bee-Bot game is facilitated through the design and implementation of appropriate educational scenarios (Komis \& Misirli, 2011).

According to Stohlman et al., (2012) the integration of mathematics and natural sciences into the school environment has a positive impact on children's behavior and interest in school, motivation for learning and the integration of goals by children. The STEM approach was designed to introduce the sciences of Engineering and Engineering into the teaching of Mathematics and Natural Sciences. STEM epistemology as an interdisciplinary approach is not only about a teaching model, but also requires the development of artifacts that follow the engineering cycle and the application of Computational Science methods in education. Students can even at young ages become "small Scientists and Engineers" where Engineering could be attributed as "Mechanics", while involved in the concept of "calculation" with real data.

In addition, this approach is based on explorationdiscovery. A class under this approach encourages students to work with each other to solve problems using question and answer techniques in conjunction with research. STREAM education is attractive to students as they enjoy discussing and solving essential problems. It offers satisfaction, as teachers participate as mediators and not only as instructors (Roberts, 2012). Learning increases because students share previous knowledge, use the best skills of their peers and tap into each other to discover new and important information

According to Roberts (2012) STEM education is not in itself a curriculum, but a way of organizing teaching. A fully integrated STEM curriculum is more easily implemented in kindergarten and primary school, where students stay with a teacher for a long time during the day compared to secondary school. A well-designed and accessible building material corner in kindergarten can be used to develop STEM activities (Christenson \& James, 2015). The development of programming concepts and algorithmic thinking in preschool children using the programmable Bee-Bot game is facilitated through the design and implementation of appropriate educational scenarios (Komis \& Misirli, 2011).

\subsection{Methodology}

Teaching intervention was based on the principles of interdisciplinarity and the discovery method in which students are either asked to answer a question, solve a problem or explain some observations in order to build knowledge (Bruner, 1997). For Bruner, learning is an active process. Students interact with the environment through explorations and manipulations of materials, interactive discussion, implementation of experiments and are satisfied with it having solved problems on their own. The aim of discovery learning according to Bruner (1997) is to motivate students to use the information and knowledge they possess to solve problems, and this can be done under many different circumstances.

The basic principle of discovery learning, according to Bruner (1997), is as mentioned above, for students to interact with the environment, through explorations and manipulations of materials, interactive discussion and the implementation of experiments, and to feel satisfied that they have solved problems on their own.

Toddlers work in small groups, in plenary, but also individually. Learning processes are designed in the context of student-centered approaches where the teacher has a guiding, organizational and supporting role (Kokkotas, 2002). He is responsible for creating a positive environment for students, for equipping the classroom with the necessary and appropriate means every time that will ensure all children the opportunity to experiment, explore and interact.

The stages of organization of teaching on the basis of the discovery method are: (a) the challenge of interest to pupils, (b) the formulation of assumptions by pupils concerning the proposed phenomenon to be negotiated, (c) the implementation of experimental activities by pupils by groups, (d) recording and evaluating observation results and drawing conclusions and (e) further applications and generalization (Dimitriadis, 2015).

The creative participation of learners is the key to success and for this reason a student-centred method of teaching is followed.

Key objectives for the ST(R)E(A)M epistemology-based work plan are:

- Understand the characteristics of learning through reflection

- Understand how learning through a project is linked to the STEM curriculum• Design and develop a program

- Learn the evaluation strategies supporting work plans

- Discover strategies and suggestions for class management (Lantz,2009).

ST(R)E(A)M attempts to transform from the level of traditional teaching-centered teaching into teaching where problem solving and discovery-exploratory learning will play a dominant role in the curriculum while providing opportunities for skills development by encouraging children to answer questions and engage in play-related activities on science, mathematics, engineering and technology. A component of the STEM methodology is problem solve. Children are looking for solutions to everyday problems such as the project we dealt with and which arose from the children themselves on a topic as common as rain.

\subsection{Presentation of the teaching proposal}

Children through the implementation of the proposed activities are led to experience and explore the path made by the raindrops, materials that sink and float in the water and materials that dissolve, to understand the importance of observation, experiments for the study of materials and natural phenomena, as well as to experiment with simple constructions (dam construction). Also based on the 
objectives of the "Child and Informatics" section of the Kindergarten Analytical Program (2001) children through the implementation of the activities are led to use appropriate software (in our proposal the game Bee-bot) to perform games of exploration (finding a more suitable route) and solving simple problems. In addition, the proposed teaching proposal is also compatible with the New Curriculum for Kindergarten (2011), which is complementary to the current curriculum.

In particular, according to the objectives of the section "Concepts and phenomena from the natural world" of the learning area of natural sciences, infants through the implementation of activities are led to express their ideas about simple natural phenomena related to rain and the water cycle and to negotiate them with others, to adopt relevant questions for investigation (with which route the Vee bot must follow in order to get the drop to where it should be). Also, in the learning area of Informatics toddlers using the programmable game Bee bot develop the ability to crisis and make decisions by resolving a specific problem (which route should Bee bot choose to collect all the garbage from the water? The apocalyptic method in which knowledge is derived as the conclusion of an experimental process is applied (Dimitriadis, 2015).

Children express opinions, exchange them, make assumptions, which they verify or not through the implementation of the following successive phases.

Phase 1/ trigger of interest

The weather has changed, and children have already noticed the changes. The rains and storms of the last few days have been a point of reference and discussion on the issue of water and rain. Through questions and brainstorming, the kindergarten teacher traced the children's views and knowledge of the phenomenon as well as their questions and recorded all this and posted them on a map in plenary which is particularly important for the continuation of our exploration and our involvement with the subject.

The children searched the classroom library for books and read one of them: The drops travel of Triantafyllia Makouli and then we heard an audio excerpt from the work of Stamatis Spanoudakis : "the raindrops". Then we divided the children into heterogeneous groups of three and drove them to the corner of the computer, where with the help of the teacher, the children using keywords : "the journey of water" and "the circle of water videos" found on the internet a video on YouTube which was short and understandable for children.

Phase 2 /Case formulation

We started conducting experiments to check whether the "cases" of our students apply (Hewitt, 2009) and the children studied information and data that we first recorded and then combined them with previous knowledge, reaching fruitful conclusions. We made assumptions and tried before carrying out the experiments, to "guess" which of the simple materials we have at our disposal, dissolved in water or not and which materials float and which do not. With regard to the experiment with immersion and navigation from the literature we know that the difficulties children face in understanding this phenomenon are proportional to the characteristics of their thinking. Thus, children tend to attach human characteristics (an object floats because it knows how to swim) or moral requirements (an object sinks because this is the right thing to do) to objects that sink or float (Selley, 1993). Moreover, they tend, by making arbitrary groupings, to consider that heavy objects sink, while light objects float, often justifying that an object is heavy enough that water cannot lift it. Similarly, because they confuse the generalized concept of size with that of weight, they class large objects into those that sink and small ones into floats (Koliopoulos et al, 2004).

Phase 3/ Experimentation

We appointed some of the class members to record the data for the experiment, and the rest of us were the observers. Focusing on questions about what children observe, not only are children helped to develop valuable communication and monitoring skills, but their confidence is needed by giving them the questions they can answer as experts

- What happened there?

- What did you try?

- What do you notice about...

- What do you think will happen if?..

The subjects in which we specialized were:

- Coagulation and Melting through Art

- The temperature of the water and its change,

- The solicit of the water were activities carried out in the classroom. Immersion and sailing of objects in water

Phase 4/Theory formulation

At this point, the teaching transformation of the content from the level of the scientific model to knowledge suitable for teaching to infants is required. This is followed by the completion of the semi-structured conceptual map in the Kidspiration conceptual mapping software to capture conceptual change.

Phase 5/ Continuous control

At this stage, knowledge is associated with wider natural phenomena, which is in line with the subject of the interdisciplinary approach of a subject In parallel with the subject of Science (S for Science) we dealt with Technology ( $\mathrm{T}$ for Technology).

$\mathrm{T}$ for Technology In Technology and in our topic Technology and Water, the toddlers here carried out a number of activities based on certain goals. Following the study of the book "The Secrets of Water" by Emmanuel Chanut, they came into contact with the kidspiration conceptual mapping software as it is a building, multi-media and hyper-media tool that utilizes the students' previous knowledge in order to create a time sequence in the phenomenon of the water cycle.

With the kidspiration software the children had to put in order images of the concept studied that were mixed on the screen, with the help of numbers with the technique "pressdrag-leave" and then we dealt with the software Hot Potatoes, a software for evaluating and embedding knowledge where children made the mapping of images of the water cycle with their appropriate names.

In Engineering, bricks and other building materials are the materials used to help children cultivate Mathematics and thus approach concepts such as balance, shapes and problem solving (Boston children's museum, STEM spoons).The children created with construction materials a snowplow and water pumps while we talked about the power of water and tried to build a dam.

Through A (Arts) the children approached the water cycle, involving the Arts, the play, dramatization, painting and 
music. The Arts gave the opportunity even physics subjects such as coagulation and melting, to become more understandable and more familiar in their age and developmental level. After all, as Vygotsky says, children can reach the Imminent Development Zone, the so-called maximum level of development, as long as we approach knowledge through their own "filter"

- Approaching the Water Cycle Through Poetry

- Music through song special composition for the circle of Water from the educational

With Mathematics (M) they were involved in making puzzles with the water cycle where the children, after discussing the water cycle, created puzzles in which the water cycle was described in sequence. They painted, cut and then assembled them, while another indicative activity among many others was the matching of numbers and raindrops where the children cut, painted and decorated the classroom and the coding and numbering of drops.

Finally, we approached the world of educational robotics and algorithmic thinking using the programmable Bee-Bot game, and through a series of activities of increasing difficulty that develop orientation and distance measurement skills. Children were given the opportunity to develop their creativity, imagination, critical thinking and the ability to solve a problem. Each student played, researched, thought, understood and discovered knowledge through experimentation by programming BeeBot to make along with the drop the Circle of Water but also to clean the Sea together with the children from plastic, bag and aluminum.

\section{CONCLUSION}

According to Kermani \& Aldemir (2015) children's experiences in the early years of life are very important for the brain and their development. Children's involvement in the natural sciences at an early age, in combination with other fields, helps them to raise awareness and increase their interest in science and school (Mantzicopoulos et al., 2009). Research has shown that attitudes and learning towards science are shaped in the early years of education and then difficult to change (Archer et al., 2010). The ST(R)E(A)M approach includes how to understand, skills and skills to address problems at the individual, group, social and wider global level (Bybee, 2010).

Through the implementation of the proposed ST(R)EAM approach, the aim is to exploit all the potential of infants, to develop their critical thinking and creativity, as well as computational thinking through computer-free activities (unplug). Attempts are made to approximate the concepts of cruising and sinking by solving a problem that activates children's interest and motivates them to take action. The construction of the raft confronts them with principles of engineering, while the attempt to sail it with problems faced by scientists in the construction of ships.

In addition, they intuitively perceive the concept of volume and mass, variables that affect density. They are introduced to programming through the programmable game Bee bot and perform routes of simple spatial concepts after first counting the steps required. Finally, solving the problem is the result of a team effort and cooperation. It is therefore clear that the ST(R)E(A)M approach contributes to the cultivation of the scientific literacy of infants and the skills that will enable them to act actively and responsibly in society. It also prepares students for skills that will be required of them as future workers and citizens.

This is achieved by linking knowledge with everyday life and activating student participation by formulating questions, solving problems, group work. They become literate at the scientific and technological level, respond to complex problems, propose solutions and develop their communication and collaborative skills. Therefore, several countries have proceeded to draw up ST(R)E(A)M analytical programs for each level of education. The term ST(R)E(A)M is a "label" on what teachers are already working on in the classroom. It is an innovative approach to the design of Analytical Curriculums, in which the courses of Natural Sciences, Technology, Engineering and Mathematics are treated not as separate teaching subjects but as a "whole", removing barriers between sciences.

Dewey at the beginning of the 20th century had written: "We do not have a series of separate worlds, another mathematician, another physicist, another historian. We live in a world where all sides are connected, all studies come from relationships of a great common world and as the child lives in a changing and energetic relationship with this common world, his studies are naturally single" (Dewey, 1990).

\section{ACKNOWLEDGMENT}

Paraskevi Foti, thanks the $4^{\text {th }}$ Kindergarten of Agia Varvara, in Greece and especially, her little students whose imagination and tendency to experimentation and exploration gave her the strength to discover with them new paths of knowledge.

\section{REFERENCES}

Archer, L., DeWitt, J., Osborne, J., Dillon, J., Willis, B. \& Wong, B. (2010) 'Doing' science versus 'being' a scientist: Examining 10/11-year-old schoolchildren's constructions of science through the lens of identity. Science Education, 94(4), 617-639.

Bruner, J. (1997). Acts of meaning. Athens: Greek Letters.

Bybee, R. W. (2010). Advancing STEM Education: A 2020 Vision. Technology and Engineering Teacher, 70(1), 30-35

Christenson, L. \& James, J (2015) Building Bridges to Understanding: STEM in the Pre-KClassroom. Young Children. (70)1.

Dewey, J. (1990). The School and Society: The Child and the Curriculum. Chicago, IL: University of Chicago Press.

Dimitriadis, S. (2015). Learning theories and educational software. Retrieved June 10, 2019 from https://repository. kallipos.gr/handle/11419/3397.

Hewitt, P.G., (2009). The Concepts of Physics. University publications of Crete.

Kermani, H., \& Aldemir, J. (2015). Preparing children for success: integrating science, math, and technology in early childhood classroom. Early Child Development and Care, 185(9), 1504-1527.

Kokkotas, P. (2002): Teaching of Natural Sciences II. Modernapproaches to the teaching of Natural Sciences, 3rd edition improved,Ed. Gregory, Athens.

Koliopoulos, D., Tandaros. S., Papandreou. M., Ravanis. K., (2004). Preschool Children's Ideas about Floating: A Qualitative Approach. Journal of Science Education, 5(1), 21-24.

Komis, V., \& Misirli, A. (2011). Robotique pédagogique et concepts préliminaires de la programmation à l'école maternelle : Une étude de cas basée sur le jouet programmable Bee-Bot. In Proceedings of the 4th conference of "Didactics of Informatics" - DIDAPRO (pp. 271-284). Athènes: New Technologies Editions.

Lantz, H. B. (2009). Science, Technology, Engineering, and Mathematics (STEM) Education. What Form? What Function? Retrieved August 10, 
2012

http://www.currtechintegrations.com/pdf/STEMEducationArticle.pdf

Lyons, C. D., \& Tredwell, C. T. (2015). Steps to implementing technology in inclusive early childhood programs. Computers in the Schools, 32(2), 152-166.

Mantzicopoulos, P., Samarapungavan, A. \& Patrick, H. (2009). We learn how to predict and be a scientist: Early science experiences and kindergarten children's social meanings about science. Cognition and Instruction, 27(4), 312-369.

Moomaw, Sally and Jaumall Davis. (2010). STEM Comes to Preschool. Young Children, 65 (5), 12-18.

Morrison, J. (2006). TIES STEM education monograph series, Attributes of STEM education. Baltimore, MD: TIES

Morrison, J., \& Bartlett, R. V. (2009). STEM as a curriculum: An experiential approach. Education Week, 28(23), 28-31.

Quigley, C. F., Herro, D., \& Jamil, F. M. (2017). Developing a conceptual model of STEAM teaching practices. School Science and Mathematics, 117, 1-12.

Roberts, A. (2012). A Justification for STEM Education. Technology and Engineering Teacher. May/June 2012.

Selley, N. (1993). Why do things float: A study of the place for alternative models in school science. SSR, 74(269), 55-61.

Stohlmann, M., Moore, J. T. \& Roehrig, H. G. (2012). Considerations for Teaching Integrated STEM Education. Journal of Pre-College Engineering Education Research (J-PEER), 2(1), 28-34.

Tsupros, N., Kohler, R., \& Hallinen, J. (2009). STEM education: A project to identify the missing components. Intermediate Unit 1: Center for STEM Education and Leonard Gelfand Center for Service Learning and Outreach, Carnegie Mellon University, Pennsylvania.

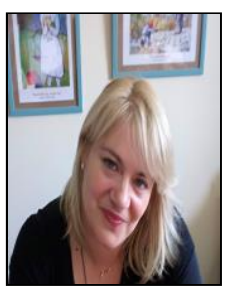

Paraskevi Foti is a Coordinator of the Primary and Secondary Education at the 3rd Region of Attica (Greek Ministry of Education) and formerly Head of the 4th Kindergarten of Agia Varvara. She has studied piano and higher theory at the National Conservatory of Athens and has completed her master's degree in Intercultural Education and Management of Diversity. She completed her second degree in Psychology at Ethniko Kai Kapodistrian University of Athens with a specialization in Psychology and at the same department she completed her doctoral dissertation with the title: "The contribution of ancient Greek language to art and language of Aesop and the added value of ICT Technology". Her first book, entitled "Otherness, Prejudice and Stereotypes in the School Class. Teacher Management Methods" (2016, Athens: Grigoris) was selected as a university book at Harokopeio University of Athens and also, she has participated in a collective volume on Teaching Scripts through ICT. (2017, Athens: Grigoris). Her next book is called: "Understanding our language, ancient and modern Greek through Aesop" (2020, Athens : Grigoris ed.) and the next book is called : "S.T.(R).E.A.M. and Educational Robotics for children from 3 up to 8 years old" (2020, Athens: Grigoris ed.). She has published in international and national conference proceedings as well as in scientific journals and has a keen interest in Information and Communication Technologies and their contribution to the teaching process while being an eTwinning and Moodle trainer in support of open source software. She is a Researcher Associator in the Early Childhood Department of Education and Care at the University of West Attica teaching the courses in "Children's Literature" and "Pedagogy of Image" and in the Interdisciplinary Program of Pedagogy through New Technologies.nd the other authors may include biographies at the end of regular papers. 